\title{
Consórcio de milho com braquiária e guandu-anão em sistema de dessecação parcial
}

\author{
Priscila de Oliveira(1), João Kluthcouski(2), José Laércio Favarin ${ }^{(3)}$ e Darliane de Castro Santos(4)
}

\begin{abstract}
(1)Embrapa Cerrados, Caixa Postal 08223, CEP 73310-970 Planaltina, DF. E-mail: priscila.oliveira@cpac.embrapa.br (2)Embrapa Arroz e Feijão, Caixa Postal 179, CEP 75375-000 Santo Antônio de Goiás, GO. E-mail: joaok@cnpaf.embrapa.br (3)Universidade de São Paulo, Escola Superior de Agricultura Luiz de Queiroz, Departamento de Produção Vegetal, Caixa Postal 9, CEP 13418-900 Piracicaba, SP. E-mail: jlfavari@esalq.usp.br (4)Universidade de Brasília, Faculdade de Agronomia e Veterinária, Instituto Central de Ciências, Ala Sul, Caixa Postal 4.508, CEP 70910-970 Brasília, DF. E-mail: darliane.castro@gmail.com
\end{abstract}

Resumo - O objetivo deste trabalho foi avaliar a viabilidade do consórcio de milho (Zea mays) cv. BRS 1035 com braquiária (Urochloa brizantha) e guandu-anão (Cajanus cajan), no sistema de dessecação parcial. Os experimentos foram realizados na safra de verão de 2008/2009, em Santo Antônio de Goiás, GO e Ipameri, GO, em blocos completos ao acaso, com cinco repetições. Os tratamentos constituíram-se de cultivos de milho, em consórcio com braquiária e guandu-anão, com a aplicação de nitrogênio mineral em cobertura, à emergência da cultura ou aos 20 dias após esse evento, com ou sem aplicação de subdose de herbicida à braquiária não dessecada. A viabilidade do sistema de dessecação parcial é dependente do manejo da adubação nitrogenada do milho ou do controle do crescimento da braquiária nas faixas não dessecadas.

Termos para indexação: Brachiaria, Zea mays, culturas intercalares, curva de crescimento, índice de área foliar, produtividade.

\section{Maize intercropped with palisadegrass and pigeon pea in partial desiccation system}

\begin{abstract}
The objective of this work was to assess the viability of maize (Zea mays) cultivar BRS 1035 intercropped with palisadegrass (Urochloa brizantha) and pigeon pea (Cajanus cajan) in the partial desiccation system. The experiments were performed in the summer season of 2008/2009, in Santo Antônio de Goiás, GO and Ipameri, GO, Brazil, in a complete randomized block design, with five replicates. The treatments consisted of maize intercropped with palisadegrass and pigeon pea, with mineral nitrogen application on maize, on the day of its emergence, or 20 days after this event, with or without the application of a herbicide subdose on palisadegrass not desiccated. The viability of the partial desiccation system is dependent on the nitrogen fertilizer management of corn or on the growth control of nondesiccated palisadegrass rows.
\end{abstract}

Index terms: Brachiaria, Zea mays, alley cropping, growth curve, leaf area index, productivity.

\section{Introdução}

A dessecação parcial é um sistema em que o pulverizador é acoplado à semeadora-adubadora e, em apenas uma operação, realizam-se a adubação, a semeadura e a dessecação localizada, em cerca de $30 \%$ da área, com a linha de semeadura centralizada de maneira que o espaçamento entre linhas seja de 80 a $100 \mathrm{~cm}$. O objetivo desse sistema é a recuperação de pastagens degradadas, principalmente em solos arenosos de declive suave a fortemente ondulado, nos quais o manejo convencional do solo representa grande risco. Assim, na faixa dessecada é semeada a espécie forrageira do pasto a ser recuperado e também o guandu-anão ou outra espécie leguminosa, como forma de diversificar a forragem e aumentar o nitrogênio no solo. Além disso, pode-se inserir a cultura do milho consorciado com as forrageiras, para aumentar a renda e cobrir parcialmente os custos de implantação da pastagem (Kluthcouski \& Aidar, 2003).

Prática comum desde longa data, o consórcio pode ser definido como um sistema de cultivo em que duas ou mais culturas crescem simultaneamente na mesma área, por um período significativo de seu desenvolvimento (Willey, 1979). Em geral, entre os principais fatores que podem determinar a adoção do sistema consorciado pelo produtor destacam-se a redução de riscos de perda de produtividade, melhor 
aproveitamento da área da propriedade e maior retorno econômico (Portes, 1996).

A partir do ano 2000, o consórcio de milho com gramíneas forrageiras teve grande destaque nas propriedades rurais, e foi objeto de pesquisas. O consórcio entre essas culturas tem como objetivo produzir grãos e formar pastagem de alta qualidade nutricional, bem como palhada para o sistema plantio direto (SPD) (Kluthcouski \& Aidar, 2003; Borghi \& Crusciol, 2007). Recentemente, a utilização de espécies forrageiras leguminosas com a cultura do milho foi avaliada com resultados positivos para o milho (Rao \& Mathuva, 2000; Heinrichs et al., 2005; Nunes et al., 2006). Esses consórcios também representam diversificação de palhadas de cobertura do solo para 0 SPD, visto que a utilização de espécies com alta relação carbono:nitrogênio pode imobilizar temporariamente $o$ nitrogênio $(\mathrm{N})$ no solo. Além disso, algumas espécies de leguminosas têm sido avaliadas por diversos autores quanto à produção de fitomassa e fornecimento de nutrientes ao solo, quando cultivadas em consórcio com milho ou no monocultivo (Amabile et al., 2000; Sodré Filho et al., 2004; Heinrichs et al., 2005; Carneiro et al., 2008).

No entanto, na literatura, não foram encontrados trabalhos que tenham avaliado o consórcio simultâneo de três espécies, em área com pasto parcialmente dessecado, em que parte dessa pastagem tenha permanecido viva desde a semeadura das culturas. $\mathrm{O}$ pasto não dessecado pode competir em crescimento com a cultura do milho semeada nas faixas dessecadas. Portanto, é fundamental a realização de estudos do sistema de dessecação parcial, em que se avalie o acúmulo de matéria seca das três espécies em consórcio e a produtividade de grãos de milho, como forma de subsidiar a adoção desse sistema.

O objetivo deste trabalho foi avaliar a viabilidade do consórcio de milho (Zea mays) com braquiária, Urochloa brizantha (Hochst. ex A. Rich.) R. Webster) (Syn. Brachiaria brizantha (Hochst. ex A. Rich.) Stapf), e guandu-anão Cajanus cajan (L.) Millsp., no sistema de dessecação parcial.

\section{Material e Métodos}

Foram realizados dois experimentos, um deles na Fazenda Capivara, da Embrapa Arroz e Feijão, no Município de Santo Antônio de Goiás, GO (experimento 1), a $16^{\circ} 28^{\prime} 00^{\prime \prime} \mathrm{S}, 49^{\circ} 17^{\prime} 00^{\prime \prime} \mathrm{W}$ e $823 \mathrm{~m}$ de altitude. Segundo a classificação de Köppen, essa localidade apresenta clima Aw, tropical de savana, mesotérmico. O solo da área experimental é classificado como Latossolo Vermelho distrófico, de textura argilosa (Silva, 1999). Os atributos químicos do solo, antes da instalação do experimento, estão apresentados na Tabela 1. A área experimental utilizada tem sido manejada em rotação lavoura-pastagem, de maneira que foi mantida com pastagem de braquiária nos três anos anteriores à condução do experimento. A média da massa da matéria seca de palhada, deixada na área experimental no verão de 2008/2009 pela pastagem de braquiária dessecada, foi de $8.478 \mathrm{~kg} \mathrm{ha}^{-1}$.

Utilizou-se o delineamento experimental de blocos completos ao acaso, com cinco repetições. Cada parcela experimental tinha uma área total de $54 \mathrm{~m}^{2}$, em que $10 \mathrm{~m}^{2}$ foram considerados como área útil para a colheita. Os seis tratamentos constituíram-se de milho em monocultivo ou consorciado com braquiária e guandu-anão, com aplicação de $75 \mathrm{~kg} \mathrm{ha}^{-1} \mathrm{de} \mathrm{N}$, na forma de ureia, no dia da emergência do milho ou aos 20 dias após a emergência (DAE), e com ou sem a aplicação de subdose de herbicida nicosulfuron $\left(16 \mathrm{~g} \mathrm{ha}^{-1}\right.$ de ingrediente ativo) da seguinte forma: $\mathrm{T} 1$, sem dessecação, com adubação $\mathrm{N}$ aos $20 \mathrm{DAE}$; T2, dessecação total da área, com N aos $20 \mathrm{DAE}$; T3, dessecação parcial, com $\mathrm{N}$ ao 0 DAE; T4, dessecação parcial, com $\mathrm{N}$ ao 0 DAE e subdose de herbicida; T5, dessecação parcial, com N aos 20 DAE; e T6, dessecação parcial, com $\mathrm{N}$ aos 20 DAE e subdose de herbicida.

A dessecação do pasto foi realizada com a aplicação de glifosato (2.160 $\mathrm{g} \mathrm{ha}^{-1}$ de i.a) simultaneamente à adubação (400 $\mathrm{kg} \mathrm{ha}^{-1}$ do formulado 04-30-10) e à semeadura do milho híbrido BRS 1035 (seis sementes por metro), guandu-anão (dez sementes por metro) e braquiária $\left(10 \mathrm{~kg} \mathrm{ha}^{-1}, \mathrm{VC}=32 \%\right)$. A emergência das plântulas de milho ocorreu sete dias após a semeadura. A amostragem de plantas para a análise de crescimento foi realizada a cada sete dias, tendo-se coletado duas plantas por parcela, a partir de 16 DAE até $62 \mathrm{DAE}$, e a partir dessa época, as duas últimas coletas foram realizadas a cada 15 dias. As plantas foram armazenadas em sacos de plástico e identificadas para o transporte até o Laboratório de Agrofisiologia da Embrapa Arroz e Feijão, onde foi efetuada a separação das partes botânicas. As plantas de milho foram divididas em colmo+bainha, limbo foliar, pendão e espiga. As plantas de guandu-anão foram divididas em limbo foliar e 
pecíolos +hastes. Os limbos foliares foram submetidos ao leitor de área foliar modelo LI-3000 Area Meter (LI-COR Inc., Lincoln, NE, EUA), cuja leitura é dada em centímetros quadrados. Todas as estruturas vegetais foram submetidas à secagem em estufa a $60^{\circ} \mathrm{C}$, até massa constante, para determinação da massa de matéria seca (MS). Foram avaliadas a massa de matéria seca da parte aérea (MSPA, $\mathrm{kg} \mathrm{ha}^{-1}$ ) e o índice de área foliar (IAF, $\mathrm{m}^{2}$ de folha $\mathrm{m}^{-2}$ de solo).

Para a comparação dos dados de IAF no tempo, utilizou-se o modelo exponencial quadrático $\mathrm{IAF}=\mathrm{a} \cdot \exp \left\{-0,5[\ln (\mathrm{t} / \mathrm{b}) / \mathrm{c}]^{2}\right\}$, em que: a refere-se ao valor máximo teórico de IAF; $t$ ao número de dias após a emergência do milho (DAE); $b$ ao número de dias após a emergência do milho correspondente ao valor máximo de IAF; e c ao parâmetro empírico referente à forma da curva.

Para avaliação dos dados de MSPA, ajustou-se o modelo sigmoidal de três parâmetros $\operatorname{MSPA}=\mathrm{a} /[1+\exp -(\mathrm{t}-\mathrm{b} / \mathrm{c})]$, em que: a refere-se ao valor máximo teórico de MSPA; $t$ ao número de dias após a emergência do milho (DAE); b ao número de dias após a emergência correspondente a $50 \%$ do valor máximo de MSPA; e c à inclinação da curva. Ambos os modelos foram ajustados pelo programa Table Curve 2D (Jandel Scientific, 1991), e a validade desses ajustes foi expressa pelos níveis de significância $(1,5$ ou $10 \%$, pelo teste $\mathrm{F}$ ) dos coeficientes estimados nos modelos ajustados.

As plantas de guandu-anão e de braquiária foram coletadas no momento da colheita das espigas de milho, para a determinação da massa da matéria seca (MS) das espécies. As plantas foram submetidas à secagem em estufa a $60^{\circ} \mathrm{C}$, e os resultados apresentados em quilograma por hectare de MS. As espigas de milho foram colhidas manualmente e trilhadas em batedora de cereais modelo BC 80 III (Nux, Itapira, SP, Brasil), cuja massa foi ajustada para $130 \mathrm{~g} \mathrm{~kg}^{-1}(13 \%)$ de umidade.
O número de espigas por planta foi calculado pela razão entre o número de espigas da área útil da parcela e a população final de milho nessa mesma área. A altura de inserção das espigas foi determinada por meio de medição da distância entre o solo e a inserção da espiga no colmo da planta. Ambas as avaliações foram realizadas no momento da colheita do milho.

$\mathrm{Na}$ análise dos dados experimentais de produtividade de milho e das forrageiras, utilizou-se o programa SAS versão 9.1 (SAS Institute, 2009), para análise de variância, tendo sido aplicado o teste de Tukey, a 5\% de probabilidade.

O experimento 2 foi realizado na Fazenda Santa Brígida, no Município de Ipameri, GO, localizada a $17^{\circ} 39^{\prime} 27^{\prime \prime S}, 48^{\circ} 12^{\prime} 22^{\prime \prime} \mathrm{W}$ e $800 \mathrm{~m}$ de altitude. Segundo a classificação de Köppen, essa localidade apresenta clima Aw, tropical de savana, mesotérmico. O solo da área experimental é classificado como Latassolo Vermelho distrófico, e seus atributos químicos estão apresentados na Tabela 1. A área encontrava-se sob SPD há seis anos, e o histórico recente é o seguinte: 2005, 2006 e 2007, soja no verão; 2008 , milho+braquiária no verão e pasto no inverno.

Utilizou-se o delineamento experimental de blocos completos ao acaso, com cinco repetições. Cada parcela experimental tinha uma área total de $36 \mathrm{~m}^{2}$, em que $10 \mathrm{~m}^{2}$ foram considerados como área útil para a colheita. Os sete tratamentos constituíram-se de milho (híbrido BRS 1035) em monocultivo ou consorciado com braquiária e guandu-anão, com fornecimento de $75 \mathrm{~kg} \mathrm{ha}^{-1}$ de $\mathrm{N}$, na forma de ureia, em três épocas de aplicação: T1, sem dessecação e sem N; T2, dessecação parcial sem N; T3, dessecação total, com $\mathrm{N}$ aos 20 DAE; T4, dessecação parcial, com $\mathrm{N}$ ao 0 DAE; T5, dessecação parcial, com $\mathrm{N}$ aos $10 \mathrm{DAE}$; e T6, dessecação parcial, com N aos 20 DAE e T7, dessecação parcial, com $\mathrm{N}$ aos $20 \mathrm{DAE}$ e subdose de nicosulfuron (16 $\mathrm{g} \mathrm{ha}^{-1}$ de i.a.). A implantação e a condução do

Tabela 1. Atributos químicos do solo nas profundidades 0-10 e 10-20 cm, anteriores à instalação dos experimentos, no verão de 2008/2009, em Santo Antônio de Goiás, GO e Ipameri, GO.

\begin{tabular}{|c|c|c|c|c|c|c|c|c|c|c|c|c|}
\hline \multirow{2}{*}{$\begin{array}{l}\text { Profundidade } \\
(\mathrm{cm})\end{array}$} & $\mathrm{pH}$ & $\mathrm{Ca}$ & $\mathrm{Mg}$ & $\mathrm{Al}$ & $\mathrm{H}+\mathrm{Al}$ & $\mathrm{P}$ & K & $\mathrm{Cu}$ & $\mathrm{Zn}$ & $\mathrm{Fe}$ & $\mathrm{Mn}$ & $\mathrm{MO}$ \\
\hline & em água & -------- & --- $(\mathrm{c}$ & $\mathrm{dm}^{-3}$ & ----------- & $-----\cdot$ & 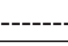 & $-(\mathrm{mg}$ & $\left.1^{-3}\right)---$ & ----- & ------ & $\left(\mathrm{g} \mathrm{dm}^{-3}\right)$ \\
\hline & \multicolumn{12}{|c|}{ Santo Antônio de Goiás, GO } \\
\hline $0-10$ & 6,8 & 4,1 & 1,6 & 0,0 & 4,4 & 7,6 & 281 & 1,7 & 3,7 & 40 & 60 & 31 \\
\hline \multirow[t]{2}{*}{$10-20$} & 6,7 & 3,9 & 1,1 & 0,0 & 4,3 & 4,9 & 156 & 1,3 & 2,4 & 15 & 50 & 26 \\
\hline & \multicolumn{12}{|c|}{ Ipameri, GO } \\
\hline $0-10$ & 6,6 & 2,5 & 1,0 & 0,0 & 3,1 & 4,5 & 218 & 2,1 & 6,8 & 33 & 38 & 20 \\
\hline $10-20$ & 6,0 & 1,5 & 0,7 & 0,0 & 4,0 & 11,4 & 72 & 3,3 & 5,6 & 41 & 23 & 17 \\
\hline
\end{tabular}


experimento 2 foram feitas conforme descritas no experimento 1 , bem como a análise estatística.

\section{Resultados e Discussão}

A maior produtividade do milho, obtida no experimento 1, ocorreu em área totalmente dessecada e com aplicação de $75 \mathrm{~kg} \mathrm{ha}^{-1}$ de $\mathrm{N}$ aos 20 DAE (Tabela 2). As faixas de pastagem não dessecadas competiram com a cultura, e o efeito prejudicial foi diminuído com a antecipação da adubação nitrogenada, no momento da emergência de milho (0 DAE), ou quando foi aplicada uma pequena dose de herbicida para inibir o crescimento da braquiária não dessecada. A antecipação da adubação nitrogenada para o dia de emergência do milho garantiu maior competitividade inicial, o que corrobora as observações de Ceretta et al. (2002), com menor redução na produtividade de grãos. Resultados semelhantes foram obtidos por Silva et al. (2005), que anteciparam a aplicação de N para o dia da semeadura, o que proporcionou maior rendimento de grãos de milho. No entanto, esses resultados não corroboram os obtidos por Pauletti \& Costa (2000) e Bortolini et al. (2001), que não observaram efeitos positivos na produtividade de milho em razão da antecipação da adubação nitrogenada.

A redução da taxa de crescimento de braquiária, consorciada com milho, decorrente da aplicação de doses reduzidas do herbicida nicosulfuron, e o consequente desenvolvimento satisfatório do milho,

Tabela 2. Altura de inserção de espiga $(\mathrm{cm})$, número de espigas por planta e produtividade de grãos $\left(\mathrm{kg} \mathrm{ha}^{-1}\right)$ de milho (híbrido BRS 1035), nos tratamentos de dessecação do pasto de braquiária, verão de 2008/2009, em Santo Antônio de Goiás, $\mathrm{GO}^{(1)}$.

\begin{tabular}{|c|c|c|c|c|c|}
\hline Dessecação $^{(2)}$ & $\mathrm{DAE}^{(3)}$ & Subdose $\left(\mathrm{g} \mathrm{ha}^{-1}\right)^{(4)}$ & Altura & № espigas & Produtividade \\
\hline Sem & 20 & 0 & - & - & - \\
\hline Total & 20 & 0 & $121 \mathrm{a}$ & $1,00 \mathrm{a}$ & $6.318 \mathrm{a}$ \\
\hline Parcial & 0 & 0 & $115 \mathrm{ab}$ & $0,96 \mathrm{a}$ & $5.087 \mathrm{~b}$ \\
\hline Parcial & 0 & 16 & $114 \mathrm{ab}$ & $0,97 \mathrm{a}$ & $5.606 \mathrm{~b}$ \\
\hline Parcial & 20 & 0 & $107 \mathrm{~b}$ & $0,94 \mathrm{a}$ & $4.313 \mathrm{c}$ \\
\hline Parcial & 20 & 16 & $112 \mathrm{ab}$ & $0,95 \mathrm{a}$ & $5.041 \mathrm{~b}$ \\
\hline$\overline{C V}(\%)$ & & & 4,92 & 4,38 & 6,27 \\
\hline DMS & & & 10,8 & 0,08 & 640 \\
\hline
\end{tabular}

(1)Médias seguidas de letras iguais, nas colunas, não diferem entre si, pelo teste Tukey, a 5\% de probabilidade. ${ }^{(2)}$ Dessecação total, aplicação de $2.160 \mathrm{~g} \mathrm{ha}^{-1}$ de i.a. de glifosato; dessecação parcial: pulverizador acoplado à semeadora-adubadora e em apenas uma operação realizam-se a adubação, a semeadura e a dessecação localizada, em cerca de $30 \%$ da área, com a linha de semeadura centralizada. ${ }^{(3)}$ Aplicação de $75 \mathrm{~kg} \mathrm{ha}^{-1}$ de nitrogênio, na forma de ureia. ${ }^{(4)}$ Subdose de i.a. de nicosulfuron. também foram observados por Cobucci \& Portela (2003) e Jakelaitis et al. (2006). A adoção dessas práticas serviu para evitar prejuízos à produtividade do milho, que foram inferiores em relação à área totalmente dessecada ( $\mathrm{N}$ aos $20 \mathrm{DAE})$; no entanto, não foram encontrados na literatura resultados de cultivo de milho em área com dessecação parcial, em faixas, da pastagem de braquiária.

No tratamento em que não houve dessecação da braquiária, mesmo com o fornecimento de $\mathrm{N}$ aos 20 DAE, não houve produção de grãos, em razão da morte das plantas. Isso se deve ao abafamento que o pasto provocou sobre a cultura granífera, de modo que apenas algumas plantas de milho cresceram nessa condição, sem que houvesse a formação de espigas durante o período de avaliação. A menor produtividade de grãos de milho foi obtida com a dessecação parcial e o fornecimento de $\mathrm{N}$ somente aos 20 DAE. Fato que pode ser atribuído à competição exercida pela braquiária, cujo crescimento não foi controlado. Tal afirmação baseia-se no resultado verificado quando se aplicou $\mathrm{N}$ na mesma época associado à subdose de herbicida na forrageira, em que a produtividade foi superior ou igual a $5.041 \mathrm{~kg} \mathrm{ha}^{-1}$, o que corrobora resultados da literatura (Cobucci \& Portela, 2003; Jakelaitis et al., 2006).

O número de espigas por planta não foi afetado pelos tratamentos, o que confirma os resultados de Bortolini et al. (2001) quanto à época de aplicação de $\mathrm{N}$, e diverge daqueles observados por Borghi \& Crusciol (2007), que obtiveram maior número de espigas por planta no monocultivo de milho, em comparação ao cultivo consorciado com braquiária. A menor altura de inserção da espiga foi obtida na aplicação de $\mathrm{N}$ aos 20 DAE e sem aplicação de subdose de herbicida, em comparação à dessecação total com fornecimento de $\mathrm{N}$ aos 20 DAE (Tabela 2). A interferência negativa exercida pela braquiária, na fase vegetativa do milho, pode, entre outras alterações, diminuir a altura de inserção da espiga (Fancelli \& Dourado Neto, 2000). Resultados semelhantes foram observados por Galon et al. (2008), na ausência de controle da Brachiaria plantaginea no cultivo de milho.

A produção de MS do guandu-anão foi baixa, em razão do crescimento inicial lento, característico dessa espécie (Calvo et al., 2010), bem como da condição de cultivo consorciado nas linhas de milho, por ser esta cultura mais competitiva (Heemst, 1985; 
Constantin et al., 2007). Contudo, a produção de MS de guandu-anão foi superior nas seguintes áreas: totalmente dessecadas ( $\left.254 \mathrm{~kg} \mathrm{ha}^{-1}\right)$; com dessecação parcial e $\mathrm{N}$ aplicado na emergência do milho, associado ou não à subdose de herbicida; e com dessecação parcial, com o fornecimento de $\mathrm{N}$ aos $20 \mathrm{DAE}$ do milho combinado com controle do crescimento da braquiária, pela aplicação de subdose de herbicida nicosulfuron (Tabela 3). Na ausência da dessecação, mesmo com aplicação de $\mathrm{N}$ aos $20 \mathrm{DAE}$, o guandu-anão teve a menor produção de massa de matéria seca, seguido pelo tratamento com dessecação parcial e aplicação de $\mathrm{N}$ aos $20 \mathrm{DAE}\left(177 \mathrm{~kg} \mathrm{ha}^{-1}\right)$. Esse resultado pode ser atribuído à competição da braquiária na produção de fitomassa do guandu-anão, na ausência da dessecação do pasto e em dessecação parcial, mesmo com a aplicação de $\mathrm{N}$ em cobertura aos 20 DAE e o estabelecimento lento do guandu-anão, também observado por Calvo et al. (2010).

A produção de MS da pastagem, no início da instalação do experimento, foi $1.550 \mathrm{~kg} \mathrm{ha}^{-1} \mathrm{em}$ média (Tabela 3). A produção de MS da braquiária, logo após a época da colheita do milho foi maior $\left(12.577 \mathrm{~kg} \mathrm{ha}^{-1}\right)$ pela ausência de dessecação e aplicação de $\mathrm{N}$ aos 20 DAE e pelo fato de não se ter estabelecido o milho. Tal resultado pode ser atribuído ao aporte de $\mathrm{N}$ e ao controle parcial da produção de fitomassa da

Tabela 3. Massa de matéria seca $\left(\mathrm{kg} \mathrm{ha}^{-1}\right)$ de guandu-anão e braquiária, consorciados com milho (híbrido BRS 1035), nos tratamentos de dessecação do pasto de braquiária, verão de 2008/2009, em Santo Antônio de Goiás, GO ${ }^{(1)}$.

\begin{tabular}{lccccc}
\hline Dessecação & (2) & DAE $^{(3)} \begin{array}{c}\text { Subdose } \\
\left(\mathrm{g} \mathrm{ha}^{-1}\right)^{(4)}\end{array}$ & Guandu-anão & \multicolumn{2}{c}{ Braquiária } \\
\cline { 5 - 6 } Sem & 20 & 0 & $117 \mathrm{c}$ & $1.165 \mathrm{a}$ & $12.577 \mathrm{a}$ \\
Total & 20 & 0 & $254 \mathrm{a}$ & $1.338 \mathrm{a}$ & - \\
Parcial & 0 & 0 & $269 \mathrm{a}$ & $1.510 \mathrm{a}$ & $2.542 \mathrm{~b}$ \\
Parcial & 0 & 16 & $280 \mathrm{a}$ & $1.867 \mathrm{a}$ & $1.605 \mathrm{~b}$ \\
Parcial & 20 & 0 & $177 \mathrm{~b}$ & $1.947 \mathrm{a}$ & $1.938 \mathrm{~b}$ \\
Parcial & 20 & 16 & $280 \mathrm{a}$ & $1.472 \mathrm{a}$ & $1.605 \mathrm{~b}$ \\
\hline Média & & & 230 & 1.550 & 4.053 \\
\hline CV $(\%)$ & & & 8,4 & 26,8 & 10,7 \\
DMS & & & 44 & 826 & 967 \\
\hline
\end{tabular}

(1)Médias seguidas de letras iguais, nas colunas, não diferem entre si, pelo teste de Tukey, a $5 \%$ de probabilidade. (2)Dessecação total, aplicação de 2.160 g i.a. ha ${ }^{-1}$ de glifosato; dessecação parcial: pulverizador acoplado à semeadora-adubadora e em apenas uma operação realizam-se a adubação, a semeadura e a dessecação localizada, em cerca de $30 \%$ da área, com a linha de semeadura centralizada. ${ }^{(3)}$ Aplicação de $75 \mathrm{~kg} \mathrm{ha}^{-1}$ de nitrogênio, na forma de ureia. ${ }^{(4)}$ Subdose de i.a. de nicosulfuron. forrageira nos demais tratamentos. A produção de MS de braquiária na ausência de dessecação foi inferior ao observado por Portes et al. (2000), que obtiveram 19,6 $\mathrm{Mg} \mathrm{ha}^{-1}$ aos $117 \mathrm{DAE}$, e por Braz et al. (2005), que obtiveram 23,6 $\mathrm{Mg} \mathrm{ha}^{-1}$ aos 107 DAE. Essa diferença, além de se considerarem as condições edafoclimáticas locais, pode ser atribuída ao fato de a pastagem de braquiária, no presente trabalho, ter sido implantada três anos antes do início do experimento, enquanto os dados desses autores foram obtidos no primeiro ano de produção da pastagem.

Em relação à análise de crescimento das plantas (Figura 1) observaram-se maiores valores de IAF de milho entre 3,1 e $3,5 \mathrm{~m}^{2} \mathrm{~m}^{-2}$, em todos os tratamentos, exceto quando não foi feita a dessecação da braquiária, situação em que o crescimento e desenvolvimento do milho foram prejudicados pela forrageira (Figura $1 \mathrm{~A}$ ). Esses valores corroboram os observados por Braz et al. (2005), para milho consorciado com braquiária, e são inferiores aos obtidos por Lopes et al. (2009) no monocultivo de milho. Assim, apesar de considerada muito competitiva (Heemst, 1985; Constantin et al., 2007), a cultura do milho sofre interferência do cultivo consorciado, o que se reflete em menores valores de IAF máximo.

O IAF do milho cultivado em área totalmente dessecada tendeu a estender-se por mais tempo (Figura $1 \mathrm{~A}$ ), com valor máximo aos 70 DAE, enquanto na dessecação parcial houve antecipação do IAF máximo para 56 a $60 \mathrm{DAE}$, provavelmente em razão da competição da forrageira sobre o milho. Para o acúmulo de MSPA, houve semelhança entre o comportamento do milho e da braquiária (Figura $1 \mathrm{~B}$ ), exceto quando a braquiária não foi dessecada. Nessa condição, o milho foi abafado pela forrageira, que se desenvolveu plenamente e atingiu valores de IAF máximo próximos aos observados por Portes et al. (2000) no primeiro ano de cultivo da pastagem.

No tratamento com dessecação parcial da braquiária, associado à aplicação de subdose de herbicida para a forrageira e ao fornecimento de fertilizante nitrogenado, no dia da emergência do milho, o guandu-anão apresentou o maior acúmulo de massa de matéria seca de parte aérea (Figura 1 D). Essa observação resulta da menor competição exercida pela braquiária sobre o guandu-anão, pois o crescimento da forrageira foi reduzido pelo herbicida. Além disso, a aplicação de $\mathrm{N}$ mineral, no dia da emergência do milho, pode ter 
…........ $\mathrm{T} 1 \mathrm{y}=0,842 \exp \left[-0,5(\ln (\mathrm{x} / 59,351) / 0,328]^{2} \quad \mathrm{R}^{2}=0,91 * * \mathrm{EP}=0,10\right.$ $\longrightarrow \mathrm{T} 2 \mathrm{y}=3,191 \exp \left[-0,5(\ln (\mathrm{x} / 70,629) / 0,615]^{2} \quad \mathrm{R}^{2}=0,93 * * \mathrm{EP}=0,29\right.$ - $\cdot \Delta-\mathrm{T} 3 \mathrm{y}=3,377 \exp \left[-0,5(\ln (\mathrm{x} / 56,098) / 0,486]^{2} \quad \mathrm{R}^{2}=0,93^{* *} \mathrm{EP}=0,28\right.$ - $\multimap \mathrm{T} 4 \mathrm{y}=3,139 \exp \left[-0,5(\ln (\mathrm{x} / 59,696) / 0,551]^{2} \quad \mathrm{R}^{2}=0,95 * * \mathrm{EP}=0,22\right.$ - ๒ - T5 y $=3,506 \exp \left[-0,5(\ln (\mathrm{x} / 60,382) / 0,410]^{2} \quad \mathrm{R}^{2}=0,98 * * \mathrm{EP}=0,20\right.$ --- $---\mathrm{T} 6 \mathrm{y}=3,283 \exp \left[-0,5(\ln (\mathrm{x} / 60,893) / 0,500]^{2} \quad \mathrm{R}^{2}=0,89 * * \mathrm{EP}=0,39\right.$

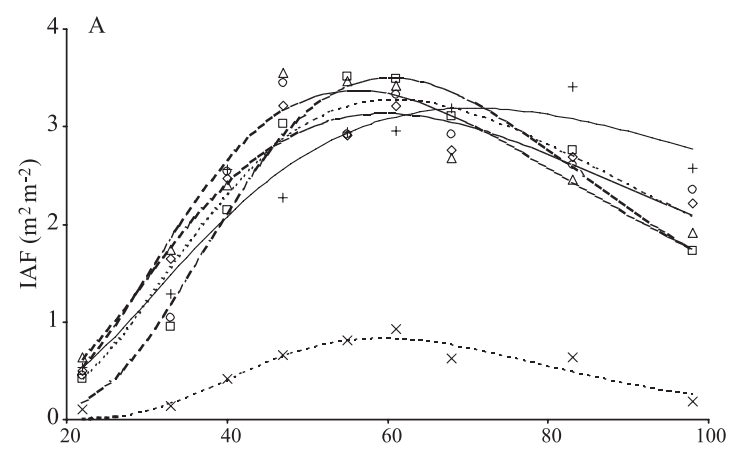

……… T1 $\mathrm{y}=0,239 \exp \left[-0,5(\ln (\mathrm{x} / 60,391) / 0,426]^{2} \quad \mathrm{R}^{2}=0,92 * * \mathrm{EP}=0,02\right.$ - $\cdot \Delta-\mathrm{T} 3 \mathrm{y}=2,013 \exp \left[-0,5(\ln (\mathrm{x} / 98,899) / 0,580]^{2} \quad \mathrm{R}^{2}=0,98^{* *} \mathrm{EP}=0,11\right.$ - $\longrightarrow \mathrm{T} 4 \mathrm{y}=4,460 \exp \left[-0,5(\ln (\mathrm{x} / 98,370) / 0,483]^{2} \quad \mathrm{R}^{2}=0,99 * * \mathrm{EP}=0,19\right.$ -・ ๒・ - T5 y $=2,480 \exp \left[-0,5(\ln (\mathrm{x} / 84,370) / 0,470]^{2} \quad \mathrm{R}^{2}=0,99 * * \mathrm{EP}=0,11\right.$ --๑-- $\mathrm{T} 6 \mathrm{y}=2,790 \exp \left[-0,5(\ln (\mathrm{x} / 80,207) / 0,450]^{2} \quad \mathrm{R}^{2}=0,98^{* *} \mathrm{EP}=0,15\right.$

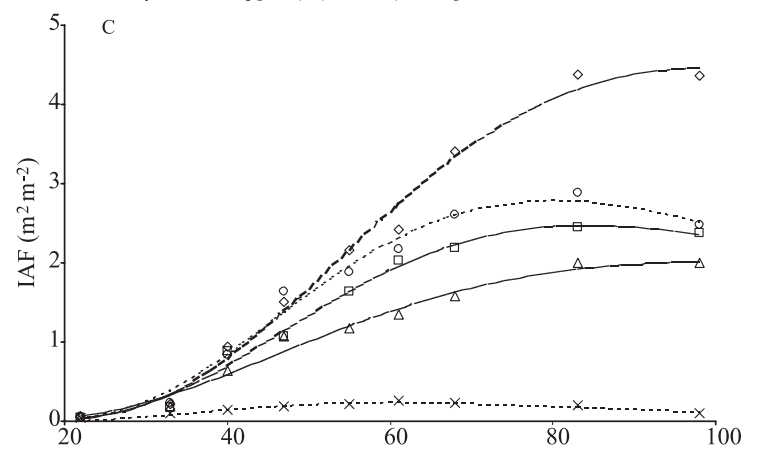

…......... T1 $\mathrm{y}=4,780 \exp \left[-0,5(\ln (\mathrm{x} / 101,041) / 0,655]^{2} \quad \mathrm{R}^{2}=0,97 * * \mathrm{EP}=0,27\right.$ - $\Delta-\mathrm{T}$ T3 $\mathrm{y}=3,105 \exp \left[-0,5(\ln (\mathrm{x} / 79,791) / 0,542]^{2} \quad \mathrm{R}^{2}=0,92^{* *} \mathrm{EP}=0,30\right.$ $\longrightarrow$ - $\mathrm{T} 4 \mathrm{y}=2,960 \exp \left[-0,5(\ln (\mathrm{x} / 84,913) / 0,456]^{2} \quad \mathrm{R}^{2}=0,99 * * \mathrm{EP}=0,08\right.$ - • - T $\mathrm{T} 5 \mathrm{y}=3,095 \exp \left[-0,5(\ln (\mathrm{x} / 99,285) / 0,364]^{2} \quad \mathrm{R}^{2}=0,97 * \mathrm{EP}=0,18\right.$ ---๑-- $\mathrm{T} 6 \mathrm{y}=3,205 \exp \left[-0,5(\ln (\mathrm{x} / 99,152) / 0,618]^{2} \quad \mathrm{R}^{2}=0,99 * * \mathrm{EP}=0,12\right.$

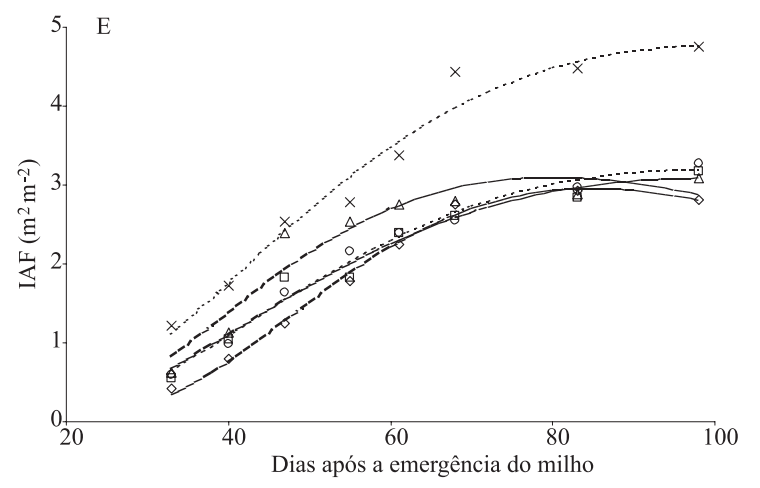

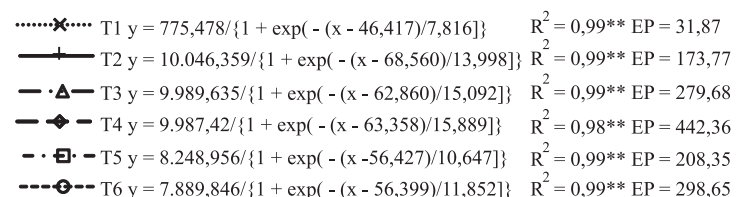

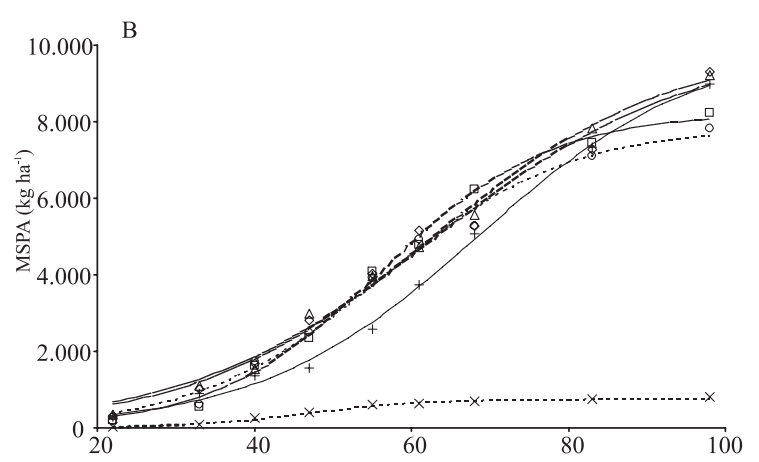

………. T1 $\mathrm{y}=52,174 /\{1+\exp [-(\mathrm{x}-47,776) / 7,602]\} \quad \mathrm{R}^{2}=0,99 * * \mathrm{EP}=2,35$

- $\cdot \Delta-\mathrm{T}$ T3 $\mathrm{y}=795,481 /\{1+\exp [-(\mathrm{x}-107,329) / 21,330]\} \mathrm{R}^{2}=0,99^{* *} \mathrm{EP}=11,67$

$\longrightarrow-\mathrm{T} 4 \mathrm{y}=536,682 /\{1+\exp [-(\mathrm{x}-74,298) / 15,911]\} \quad \mathrm{R}^{2}=0,98 * * \mathrm{EP}=22,76$

- •も. - T5 $\mathrm{y}=307,463 /\{1+\exp [-(\mathrm{x}-70,604) / 15,262]\} \mathrm{R}^{2}=0,99^{* *} \mathrm{EP}=12,18$

---๑-- $\mathrm{T} 6 \mathrm{y}=291,220 /\{1+\exp [-(\mathrm{x}-63,949) / 14,919]\} \mathrm{R}^{2}=0,98^{* *} \mathrm{EP}=12,92$

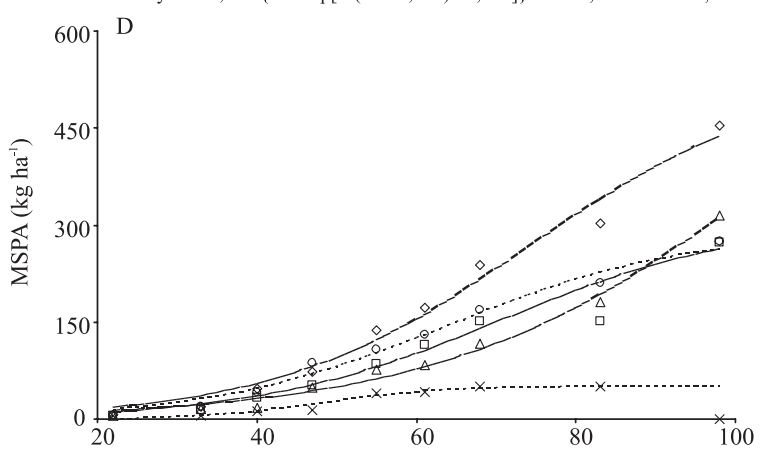

…......... T1 $\mathrm{y}=4.497,263 /\{1+\exp [-(\mathrm{x}-51,670) / 11,580]\} \mathrm{R}^{2}=0,97 * * \mathrm{EP}=266,74$

- $\Delta-\mathrm{T}$ T3 $\mathrm{y}=3.179,095 /\{1+\exp [-(\mathrm{x}-51,833) / 8,594]\} \quad \mathrm{R}^{2}=0,99 * * \mathrm{EP}=69,15$

$\longrightarrow-\mathrm{T} 4 \mathrm{y}=2.521,416 /\{1+\exp [-(\mathrm{x}-43,703) / 5,206]\} \quad \mathrm{R}^{2}=0,99 * * \mathrm{EP}=71,67$

- • • - T5 $y=3.975,831 /\{1+\exp [-(\mathrm{x}-56,520) / 9,208]\} \quad \mathrm{R}^{2}=0,99 * * \mathrm{EP}=187,02$

---๑-- T6 $\mathrm{y}=3.574,696 /\{1+\exp [-(\mathrm{x}-52,525) / 8,765]\} \quad \mathrm{R}^{2}=0,99 * * \mathrm{EP}=128,28$

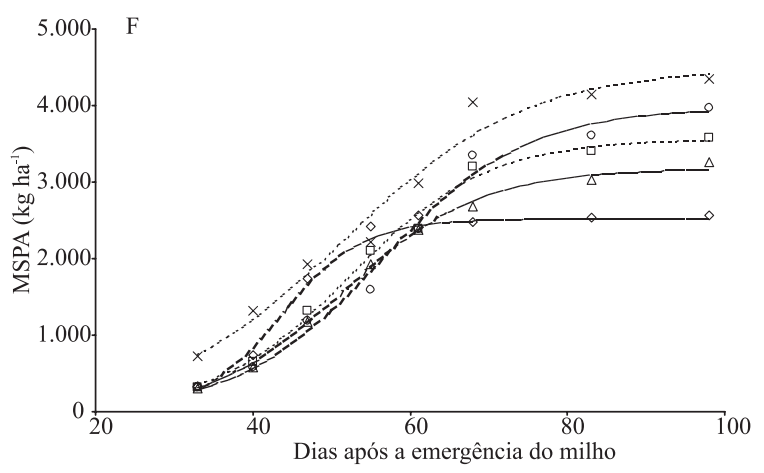

Figura 1. A, B, índice de área foliar (IAF) e massa da matéria seca da parte aérea (MSPA) de milho (híbrido BRS 1035); C, D, guandu-anão; e E, F, braquiária, verão de 2008/2009 em Santo Antônio de Goiás, GO. T1, sem dessecação, com N aos 20 DAE; T2, dessecação total da área, com N aos 20 DAE; T3, dessecação parcial, com N ao 0 DAE; T4, dessecação parcial, com $\mathrm{N}$ ao 0 DAE e subdose de nicosulfuron (16 $\mathrm{g} \mathrm{ha}^{-1}$ de i.a.); T5, dessecação parcial, com N aos 20 DAE; e T6, dessecação parcial, com N aos 20 DAE e subdose de nicosulfuron (16 $\mathrm{g} \mathrm{ha}^{-1}$ de i.a. ). Dessecação total, aplicação de $2.160 \mathrm{~g} \mathrm{ha}^{-1}$ de i.a. de glifosato; dessecação parcial: pulverizador acoplado à semeadora-adubadora e, em apenas uma operação, realizam-se a adubação, a semeadura e a dessecação localizada, em cerca de 30\% da área, com a linha de semeadura centralizada. 
favorecido o guandu-anão, cuja emergência ocorreu seis dias após esse evento, em que o $\mathrm{N}$ mineral estaria disponível à leguminosa. Um melhor desenvolvimento inicial de leguminosas em razão do fornecimento de N mineral também foi observado em Stylosanthes humilis (Gates \& Wilson, 1974), Sesbania rostrata (Becker et al., 1991) e Vigna unguiculata (Xavier et al., 2008). Tanto o IAF (Figura $1 \mathrm{C}$ ), quanto a massa de matéria seca da parte aérea (Figura 1 D), nas demais condições de dessecação parcial, tiveram comportamentos semelhantes, porém com menores valores. O menor acúmulo de MSPA ocorreu no tratamento sem dessecação da braquiária. Com base nisso, entende-se que o desenvolvimento do guandu-anão foi influenciado, primordialmente, pela adubação nitrogenada fornecida ao milho. Uma vez estabelecido, o seu crescimento foi afetado, em parte, pela competição da braquiária.

A braquiária apresentou IAF entre 2,9 e $3,2 \mathrm{~m}^{2} \mathrm{~m}^{-2}$ na dessecação parcial. $\mathrm{Na}$ avaliação do consórcio braquiária-milho, em que a forrageira foi semeada na linha do milho, Portes et al. (2000) obtiveram IAF entre 1,5 e $2,9 \mathrm{~m}^{2} \mathrm{~m}^{-2}$ aos 82 DAE. No presente experimento, para a condição sem dessecação da braquiária, observou-se IAF máximo de $4,8 \mathrm{~m}^{2} \mathrm{~m}^{-2}$ (Figura $1 \mathrm{E}$ ), enquanto Portes et al. (2000) verificaram IAF igual a $8,0 \mathrm{~m}^{2} \mathrm{~m}^{-2}$, no primeiro ano de monocultivo da forrageira. Braz et al. (2005) obtiveram IAF de $15,2 \mathrm{~m}^{2} \mathrm{~m}^{-2}$ aos $125 \mathrm{DAE}$, também no primeiro ano de produção da forrageira em monocultivo.

A produção de fitomassa da parte aérea da braquiária seguiu a ordem decrescente de acúmulo: sem dessecação, dessecação parcial com $\mathrm{N}$ aos $20 \mathrm{DAE}$; dessecação parcial com $\mathrm{N}$ aos 20 DAE e subdose de herbicida; dessecação parcial com $\mathrm{N}$ ao $0 \mathrm{DAE}$; dessecação parcial com $\mathrm{N}$ ao 0 DAE e subdose de herbicida. Esse último tratamento foi a pior condição para o crescimento da braquiária (Figura $1 \mathrm{~F}$ ). No entanto, este foi um dos tratamentos com dessecação parcial em que a produtividade de milho foi satisfatória. Como o objetivo do sistema é recuperar pastagens com redução de custos, deve-se priorizar a produtividade de grãos de milho, pois, após a sua colheita, a tendência da braquiária é acumular grandes quantidades de MS, em virtude da maior disponibilidade de radiação solar, pela ausência do dossel do milho (Portes et al., 2000; Jakelaitis et al., 2010).
A produtividade do milho (BRS 1035), no experimento 2, foi superior em área totalmente dessecada e semelhante à do experimento 1 (Tabelas 2 e 4 ). $\mathrm{Na}$ dessecação parcial, o atraso da aplicação de $\mathrm{N}$ prejudicou a produtividade do milho, exceto quando o fornecimento de $\mathrm{N}$ aos 20 DAE foi combinado ao uso de subdose de herbicida, para o controle parcial da forrageira. Tal observação indica que, na dessecação parcial, a adubação nitrogenada deve ser antecipada e não deve ultrapassar os primeiros $10 \mathrm{DAE}$. Se houver atraso no fornecimento de N, além de 10 DAE, devese usar a subdose de herbicida para o controle do crescimento da forrageira. As menores produtividades de milho foram obtidas nos cultivos sem dessecação e dessecação parcial sem N, em razão de apenas algumas plantas terem sobrevivido sob grande competição da braquiária. Contudo, essas baixíssimas produtividades não são economicamente viáveis, o que confirma a não recomendação do cultivo de milho em pastagem não dessecada em área total. Assim, o cultivo do milho não deve ser realizado no sistema de dessecação parcial sem o fornecimento de $\mathrm{N}$.

A maior produção de MS da braquiária foi obtida quando não foi feita a dessecação da forrageira (Tabela 4), com resultado inferior ao observado no

Tabela 4. Altura de inserção de espiga $(\mathrm{cm})$, número de espigas por planta, produtividade de grãos $\left(\mathrm{kg} \mathrm{ha}^{-1}\right)$ do milho híbrido BRS 1035, e produção de massa de matéria seca (MS, kg ha-1) da braquiária, nos tratamentos de dessecação do pasto, no verão de 2008/2009, em Ipameri, GO ${ }^{(1)}$.

\begin{tabular}{lcccccc}
\hline Dessecação & DAE \\
& -5 & 0 & $56,6 \mathrm{~d}$ & $0,21 \mathrm{~b}$ & $91 \mathrm{e}$ & $9.371 \mathrm{a}$ \\
$\left(\mathrm{g} \mathrm{ha}^{-1}\right)^{(4)}$ & $\begin{array}{c}\text { Altura } \\
(\mathrm{cm})\end{array}$ & $\begin{array}{c}\text { № } \\
\text { espigas }\end{array}$ & $\begin{array}{c}\text { Produtividade } \\
\left(\mathrm{kg} \mathrm{ha}^{-1}\right)\end{array}$ & $\begin{array}{c}\text { MS } \\
\left(\mathrm{kg} \mathrm{ha}^{-1}\right)\end{array}$ \\
\hline Sem & - & 0 & $72,8 \mathrm{c}$ & $0,24 \mathrm{~b}$ & $515 \mathrm{e}$ & $2.749 \mathrm{bc}$ \\
Parcial & 20 & 0 & $128,6 \mathrm{a}$ & $0,97 \mathrm{a}$ & $6.393 \mathrm{a}$ & $1.040 \mathrm{~d}$ \\
Total & 0 & 0 & $123,6 \mathrm{a}$ & $0,98 \mathrm{a}$ & $5.453 \mathrm{~b}$ & $3.129 \mathrm{~b}$ \\
Parcial & 10 & 0 & $122,6 \mathrm{a}$ & $0,93 \mathrm{a}$ & $4.516 \mathrm{c}$ & $3.649 \mathrm{~b}$ \\
Parcial & 20 & 0 & $99,6 \mathrm{~b}$ & $0,96 \mathrm{a}$ & $3.640 \mathrm{~d}$ & $3.215 \mathrm{~b}$ \\
Parcial & 20 & 16 & $125,2 \mathrm{a}$ & $0,95 \mathrm{a}$ & $4.745 \mathrm{bc}$ & $2.009 \mathrm{~cd}$ \\
Parcial & & & 6,42 & 5,36 & 10,6 & 14,0 \\
CV $(\%)$ & & & 13,6 & 0,08 & 783 & 1.023 \\
DMS & & & & & &
\end{tabular}

(1)Médias seguidas de letras iguais, minúsculas, nas colunas, não diferem entre si pelo teste de Tukey, a 5\% de probabilidade. (2)Dessecação total, aplicação de $2.160 \mathrm{~g} \mathrm{ha}^{-1}$ de i.a. de glifosato; dessecação parcial: pulverizador acoplado à semeadora-adubadora e, em apenas uma operação, realizam-se a adubação, a semeadura e a dessecação localizada, em cerca de $30 \%$ da área, com a linha de semeadura centralizada. ${ }^{(3)}$ Aplicação de $75 \mathrm{~kg} \mathrm{ha}^{-1}$ de nitrogênio, na forma de ureia. ${ }^{\left({ }^{4}\right)}$ Subdose de i. a. de nicosulfuron. ${ }^{(5)}$ Sem aplicação de nitrogênio. 
experimento 1, assim como constatado em outros trabalhos (Portes et al., 2000; Braz et al., 2005).

A baixa produção de MS da forrageira, na dessecação total na presença de $\mathrm{N}$ aos $20 \mathrm{DAE}$, pode ser explicada pela reinfestação tardia, que ocorreu em consequência do banco de sementes de braquiária na área. A produção de MS da forrageira, associada à dessecação parcial e às aplicações de $\mathrm{N}$ aos 20 DAE e de subdose de herbicida, foi consequência, basicamente, do uso da subdose de herbicida e da falta de $\mathrm{N}$, como indica o resultado da dessecação parcial sem o fornecimento de $\mathrm{N}\left(2.749 \mathrm{~kg} \mathrm{ha}^{-1}\right)$. Há semelhança entre os resultados das dessecações parciais, com fornecimento de $\mathrm{N}$ a 0,10 e 20 DAE, que corroboram os resultados obtidos por Portes et al. (2000), para braquiária consorciada com culturas graníferas, em área totalmente dessecada.

\section{Conclusões}

1. A viabilidade do sistema de dessecação parcial é dependente do manejo da adubação nitrogenada no milho ou do controle do crescimento da braquiária nas faixas não dessecadas.

2. O cultivo de milho em área de pastagem, sem dessecação da área total, não é viável.

\section{Agradecimentos}

À Coordenação de Aperfeiçoamento de Pessoal de Nível Superior, por concessão de bolsa; à Embrapa Arroz e Feijão, pelo suporte técnico, e à Financiadora de Estudos e Projetos, pelo suporte finanaceiro.

\section{Referências}

AMABILE, R.F.; FANCELLI, A.F.; CARVALHO, A.M. de. Comportamento de espécies de adubos verdes em diferentes épocas de semeadura e espaçamentos na Região dos Cerrados. Pesquisa Agropecuária Brasileira, v.35, p.47-54, 2000.

BECKER, M.; DIEKMANN, K.H.; LADHA, J.K.; DE DATTA, S.K.; OTTOW, J.C.G. Effect of NPK on growth and nitrogen fixation of Sesbania rostrata as a green manure for lowland rice (Oryza sativa L.). Plant and Soil, v.132, p.149-158, 1991.

BORGHI, E.; CRUSCIOL, C.A.C. Produtividade de milho, espaçamento e modalidade de consorciação com Brachiaria brizantha em sistema plantio direto. Pesquisa Agropecuária Brasileira, v.42, p.163-171, 2007.

BORTOLINI, C.G.; SILVA, P.R.F. da; ARGENTA, G.; FORSTHOFE, E.L. Rendimento de grãos de milho cultivado após aveia-preta em resposta à adubação nitrogenada e regime hídrico. Pesquisa Agropecuária Brasileira, v.36, p.1101-1106, 2001.

BRAZ, A.J.B.P.; KLIEMANN, H.J.; SILVEIRA, P.M. da. Produção de fitomassa de espécies de cobertura em Latossolo Vermelho distroférrico. Pesquisa Agropecuária Tropical, v.35, p.55-64, 2005.

CALVO, C.L.; FOLONI, J.S.S.; BRANCALIÃO, S.R. Produtividade de fitomassa e relação $\mathrm{C} / \mathrm{N}$ de monocultivos e consórcios de guandu-anão, milheto e sorgo em três épocas de corte. Bragantia, v.69, p.77-86, 2010.

CARNEIRO, M.A.C.; CORDEIRO, M.A.S.; ASSIS, P.C.R.; MORAES, E.S.; PEREIRA, H.S.; PAULINO, H.B.; SOUZA, E.D. de. Produção de fitomassa de diferentes espécies de cobertura e suas alterações na atividade microbiana de solo de Cerrado. Bragantia, v.67, p.455-462, 2008.

CERETTA, C.A.; BASSO, C.J.; FLECHA, A.M.T.; PAVINATO, P.S.; VIEIRA, F.C.B.; MAI, M.E.M. Manejo da adubação nitrogenada na sucessão aveia/milho, no sistema plantio direto. Revista Brasileira de Ciência do Solo, v.26, p.163-171, 2002.

COBUCCI, T.; PORTELLA, C.M. de O. Manejo de herbicidas no sistema Santa Fé e na braquiária como fonte de cobertura morta. In: KLUTHCOUSKI, J.; STONE, L.F.; AIDAR, A. (Ed). Integração lavoura-pecuária. Santo Antônio de Goiás: Embrapa-CNPAF, 2003. p.443-458.

CONSTANTIN, J.; OLIVEIRA JUNIOR, R.S.; CAVALIERI, S.D.; ARANTES, J.G.Z.; ALONSO, D.G.; ROSO, A.C.; COSTA, J.M. Interação entre sistemas de manejo e de controle de plantas daninhas em pós-emergência afetando o desenvolvimento e a produtividade do milho. Planta Daninha, v.25, p.513-520, 2007.

FANCELLI, L.A.; DOURADO NETO, D. Manejo de plantas daninhas. In: FANCELLI, L.A.; DOURADO NETO, D. (Ed.). Produção de milho. Guaíba: Agropecuária, 2000. p.183-215.

GALON, L.; PINTO, J.J.O.; ROCHA, A.A.; CONCENÇO, G.; SILVA, A.F.; ASPIAZÚ, I.; FERREIRA, E.A.; FRANÇA, A.C.; FERREIRA, F.A.; AGOSTINETTO, D.; PINHO, C.F. Períodos de interferência de Brachiaria plantaginea na cultura do milho na região sul do Rio Grande do Sul. Planta Daninha, v.26, p.779-788, 2008.

GATES, C.T.; WILSON, J.R. The interaction of nitrogen and phosphorus on the growth, nutrient status and nodulation of Stylosanthes humilis H.B.K. (Townsville stylo). Plant and Soil, v.41, p.325-333, 1974.

HEEMST, H.D.G. van. The influence of weed competition on crop yield. Agricultural Systems, v.18, p.81-83, 1985.

HEINRICHS, R.;VITTI, G.C.; MOREIRA, A.; FIGUEIREDO, P.A.M. de; FANCELLI, A.L.; CORAZZA, E.J. Características químicas de solo e rendimento de fitomassa de adubos verdes e de grãos de milho, decorrente do cultivo consorciado. Revista Brasileira de Ciência do Solo, v.29, p.71-79, 2005.

JAKELAITIS, A.; DANIEL, T.A.D.; ALEXANDRINO, E.; SIMÕES, L.P.; SOUZA, K.V.; LUDTKE, J. Cultivares de milho e de gramíneas forrageiras sob monocultivo e consorciação. Pesquisa Agropecuária Tropical, v.40, p.380-387, 2010. 
JAKELAITIS, A.; SILVA, A.A. da; SILVA, A.F. da; SILVA, L.L. da; FERREIRA, L.R.; VIVIAN, R. Efeitos de herbicidas no controle de plantas daninhas, crescimento e produção de milho e Brachiaria brizantha em consórcio. Pesquisa Agropecuária Tropical, v.36, p.53-60, 2006.

JANDEL SCIENTIFIC. Table curve: curve fitting software. Corte Madera: Jandel Scientific, 1991. 280p.

KLUTHCOUSKI, J.; AIDAR, H. Implantação, condução e resultados obtidos com o sistema Santa Fé. In: KLUTHCOUSKI, J.; STONE, L.F.; AIDAR, H. (Ed.). Integração lavoura-pecuária. Santo Antônio de Goiás: Embrapa Arroz e Feijão, 2003. p.407-441.

LOPES, J.P.; MACHADO, E.C.; DEUBER, R.; MACHADO, R.S. Análise de crescimento e trocas gasosas na cultura de milho em plantio direto e convencional. Bragantia, v.68, p.839-848, 2009.

NUNES, H.V.; SILVA, I. de F. da; BRUNO, R. de L.A.; BARROS, D.I.; PEREIRA, W.E. Influência de sistemas de culturas, mucuna-preta e adubação mineral sobre a qualidade fisiológica de sementes de milho. Revista Brasileira de Sementes, v.28, p.6-12, 2006.

PAULETTI, V.; COSTA, L.C. Época de aplicação de nitrogênio no milho cultivado em sucessão à aveia-preta no sistema plantio direto. Ciência Rural, v.30, p.599-603, 2000.

PORTES, T. de A. A produção de feijão nos sistemas consorciados. Goiânia: Embrapa-CNPAF, 1996. 50p. (Embrapa-CNPAF. Documentos, 71).
PORTES, T. de A.; CARVALHO, S.I.C. de; OLIVEIRA, I.P. de; KLUTHCOUSKI, J. Análise do crescimento de uma cultivar de braquiária em cultivo solteiro e consorciado com cereais. Pesquisa Agropecuária Brasileira, v.35, p.1349-1358, 2000.

RAO, M.R.; MATHUVA, M.N. Legumes for improving maize yields and income in semi-arid Kenya. Agriculture, Ecosystems and Environment, v.78, p.123-137, 2000.

SAS INSTITUTE. SAS user's guide: statistics. Version. 9.1. Cary: SAS Institute, 2009.

SILVA, E.C.; FERREIRA, S.M.; SILVA, G.P.; ASSIS, R.L.; GUIMARÃES, G.L. Épocas e formas de aplicação de nitrogênio no milho sob plantio direto em solo de Cerrado. Revista Brasileira de Ciência do Solo, v.29, p.725-733, 2005.

SILVA, F.C. da (Org.). Manual de análises químicas de solos, plantas e fertilizantes. Brasília: Embrapa Comunicação para Transferência de Tecnologia, 1999. 370p.

SODRÉ FILHO, J.; CARDOSO, A.N.; CARMONA, R.; CARVALHO, A.M. de. Fitomassa e cobertura do solo de culturas de sucessão ao milho na Região do Cerrado. Pesquisa Agropecuária Brasileira, v.39, p.327-334, 2004.

WILLEY, R.W. Intercropping: its importance and research needs. Part 1. Competition and yield advantages. Field Crop Abstracts, v.32, p.1-10, 1979.

XAVIER, T.F.; ARAÚJO, A.S.F. de; SANTOS, V.B. dos; CAMPOS, F.L. Inoculação e adubação nitrogenada sobre a nodulação e a produtividade de grãos de feijão-caupi. Ciência Rural, v.38, p.2037-2041, 2008.

Recebido em 1 de junho de 2010 e aprovado em 8 de agosto de 2011 